\title{
PENGARUH KEPEMIMPINAN, DUKUNGAN ORGANISASI DAN KEADILAN TERHADAP KINERJA PEGAWAI BPJS KESEHATAN KANTOR CABANG LHOKSEUMAWAE
}

\author{
Zulikhwan \\ Universitas Islam Sumatera Utara \\ Zul.ikhwan@gmail.com
}

\begin{abstract}
An employee who feels that his work and work has the support of an organization that is and in accordance with what he hopes will definitely feel dissatisfied with the support carried out by the organization or agency where it works. The problems faced by employees in the Social Security Assurance Agency (BPJS) of the Lhokseumawe Branch Office where leadership has still not been able to implement optimizing all working human resources due to the kinship between workers and local officials so that organizational support is not based on work results and this relates to giving value to the work done by employees so as to cause a sense of injustice among employees. The sample in this study amounted to 58 people. $Y=5.271+0.083 X 1+0.833 X 2+0.331 X 3$. The multiple linear regression equation can be interpreted as follows: If the variable workload, Justice, and work environment 5,271 is equal to zero, then the performance will be worth as much as a unit with a tendency to decrease. If the workload variable is increased by 1 unit, the teacher's performance will increase by 0.083 units. If Justice is increased by 1 unit, it will be followed by an increase in teacher performance by 0.833 units.

If the work environment is improved by one unit, it will be followed by an increase in performance by 0.331 units
\end{abstract}

Keywords: Leadership, Justice, and Performance

ABSTRAK : Seorang pegawai yang merasa bahwa pekerjaan dan hasil kerjanya mendapat dukungan organisasi yang dan sesuai dengan yang diharapkannya pasti akan merasa tidak puas dengan suport yang dilakukan organisasi atau instansi tempat bekerjanya . Permasalahan yang di hadapi pegawai di Badan penyelenggara Jaminan Sosia (BPJS) Kesehatan Kantor Cabang Lhokseumawe dimana kepemimpinan masih belum dapat menerapkan mengoptimalkanseluruh sumber daya manusia yang bekerja disebabkan adanya hubungan kekerabatan antara pekerja dengan pejabat daerah sehingga dukungan organisasi yang di berikan tidak berdasarkan pada hasil kerja dan ini berhubungan dengan pemberian nilai atas pekerjaan yang di lakukan pegawai sehingga menimbulkan rasa ketidak adilan di kalangan pegawai. sampel dalam penelitian ini berjumlah 58 orang. $Y=5,271+0.083 X_{1}+0,833 X_{2}+0,331 X_{3}$. Persamaan regresi linear berganda tersebut dapat diartikan sebagai berikut :Jika variable beban kerja, Keadilan, dan lingkungan kerja 5,271 bernilai sama dengan nol, maka kinerja akan bernilai sebesar satuan dengan kecenderungan mengalami penurunan. Jika variabel beban kerja ditingkatkan sebesar 1 satuan, maka kinerja guruakan meningkat sebesar 0,083 satuan. Jika Keadilan ditingkatkan sebesar 1 satuan, maka akan diikuti dengan peningkatan kinerja guru sebesar 0.833 satuan.

Jika lingkungan kerja dintingkatkan 1 satuaan, maka akan diikuti dengan peningkatan kinerja sebesar 0,331 satuan

Kata Kunci : Kepemimpinan, Keadilan, Kinerja

\section{Pendahuluan}

Keberhasilan suatu perusahaan atau organisasi ada pada kinerja pegawai yang baik, dan terjalin harmonis secara langsung atau tidak langsung memberikan kontribusi kepada perkantoran yang meliputi kepentingan internal dan eksternal yang dimiliki oleh perkantoran. Kinerja yang baik merupakan hasil secara kualitas dan kuantitas yang dicapai oleh seorang pegawai dalam melaksanakan tugasnnya sesuai 
dengan tanggung jawab yang diberikan kepadanya maka perkantoran perlu menetapkan strategi yang tepat yaitu dengan cara memahami beberapa faktor yang mempengaruhi pencapaian kinerja antara lain efektifitas, otoritas, tanggung jawab, disiplin dan inisiatif (Keith Davis dalam Mangkunegara, 2014 : 13).

Sumberdaya manusia penting karena berperan untuk menggerakkan sumberdaya lainnya untuk mencapai tujuan organisasi. Di dalam pengelolahan SDM, apabila individu dalam organisasi yaitu sumberdaya manusianya dapat berjalan efektif maka organisasi tetap berjalan efektif. Beberapa kegiatan pengelolahan SDM misalnya pengadaan, penilaian, perlindungan, memotivasi pegawai, memberdayakan pegawai, peningkatan disiplin, bimbingan, dan lain sebagainya. Pengelolaan dan pengoptimalan sumberdaya manusia tidak lepas dari faktor pegawai. Organisasi harus mempunyai pegawai mempunyai kinerja yang baik. Dengan kata lain kelangsungan suatu organisasi ditentukan oleh kinerja pegawainya (Wirawan, 2010).

Penelitian Dewi (2012) menjelaskan bahwa kinerja merupakan suatu fungsi kemampuan pekerja dalam menerima tujuan pekerjaaan, tingkat pencapain tujuan dan interaksi antara tujuan dan kemampuan pekerja. Dengan definisi tersebut dapat dikatakan bahwa pegawai memegang peranan penting dalam menjalankan segala aktivitas perkantoran. Penelitian Ridwan (2013) menegaskan bahwa kinerja sebagai hasil kerja seseorang atau sekelompok orang dalam suatu organisasi dengan wewenang dan tanggung jawab masingmasing dalam upaya mencapai tujuan organisasi secara ilegal, tidak melanggar hukum, dan sesuai dengan moral dan etika. Kinerja pegawai adalah yang mempengaruhi seberapa banyak mereka memberi kontribusi kepada organisasi atau perbaikan kinerja baik untuk individu maupun kelompok menjadi pusat perhatian dalam upaya meningkatkan kinerja organisasi

Dari beberapa faktor diatas, untuk meningkatkan kinerja karyawan salah satunya adalah dengan memperhatikan dukungan organisasi yang berkeadilan. Organisasi selaku induk kerja harus menyediakan kepemimpinan bagaimana seorang pemimpin mampu mengarahkan menjadi penyelesai setiap persoalan yang di hadapi dalam melakukan setiap pekerjaan. Pemimpin juga mampu memancing para pegawai untuk bekerja dengan produktif. Selain itu dukungan organisasi juga sangat mampu meningkatkan kinerja pegawai dimana dukungan organisasi biasanya mampu menggerakkan sumberdaya manusia yang berada dalam satu instansi merasa terperhatikan sehingga ketika perhatian datang dari organisasi perusahaan membuat pegawai menjadi berlomba -lomba untuk bekerja secara maksimal. Untuk mencapai hasil yang optimal dalam rangka pencapaian tujuan organisasi.

Sedangkanfungsikepemimpinan yang harus dilaksanakan oleh seorang pemimpin antara lain memandu, menuntun, membimbing, membangunkan motivasi kerja, mengemudikan organisasi, menjalin jaringan komunikasi yang baik, melaksanakannya secara efisien serta membawa pegawainya pada tujuan yang telah ditentukan.

Dengan demikian maka dapat diketahui bahwa kepemimpinan pada dasarnya merupakan kemampuan yang dimiliki oleh seseorang dalam menggerakkan orang lain agar mau bekerja dengan senang hati untuk mencapai tujuan yang telah ditentukan sebelumnya. Sehubungan dengan hal tersebut diatas. Pimpinan sebagai pelaksana manajemen dalam organisasi, dituntut untuk bertindak profesional dalam menjalankan tugas sesuai dengan apa yang dibebankan kepadanya. Pimpinan harus memperlihatkan upaya lebih maju dan konkrit untuk melaksanakan fungsi manajemen dan menciptakan suasana yang kondusif sehingga tercapai tujuan sesuai dengan yang diharapkan.Dalam hal ini pimpinanorganisasi harus memberikan kontribusi yang besar bagi pengembangan profesi yang diembannya untuk kemajuan organisasi tersebut.

Kepemimpinan adalah cara seseorang pemimpin mempengaruhi perilaku bawahan agar mau bekerjasama dan bekerja secara produktif untuk mencapai tujuan organisasi. Gaya kepemimpinan yang kurang melibatkan bawahan dalam mengambil keputusan maka akan mengakibatkan adanya disharmonisasi hubungan antara pemimpin dan yang dipimpin.

Selanjutnya dukungan organisasi yang diterapkan dalam organisasi tersebut juga dapat mempengaruhi kinerja pegawai. Menurut Rhoades (2002:301) dukungan organisasi mengacu pada persepsi karyawan mengenai sejauhmana organisasi menilai kontribusi mereka dan peduli pada kesejahteraan mereka. Seorang pegawai yang merasa bahwa pekerjaan dan hasil kerjanya mendapat dukungan 
organisasi yang dan sesuai dengan yang diharapkannya pasti akan merasa tidak puas dengan support yang dilakukan organisasi atau instansi tempat bekerjanya. Selain dukungan organisasi yang didapat dukungan tersebut haruslah berdasarkan keadilan dimana rasa adil yang di berikan akan meningkatkan kinerja yang lebih besar lagi di dalam dirinya. Sedangkan keadilan yang dimaksud dimana setiap pekerjaan mendapat penghargaan yang sama antara satu karyawan dengan karyawan yang lain nyata ada perbedaan seperti menurut Greenbert dalam Pertiwi (2005 : 55) Keadilan organisasi meliputi bagaimana seorang memandang hasil yang ia terima dari perusahaan atas usaha yang telah ia lakukan untuk perusahaan selama ini dan bagaimana seseorang membandingkan antara hasil yang ia terima dengan hasil yang diterima oleh karyawan lain. Permasalahan yang di hadapi pegawai di Badan Penyelenggara Jaminan Sosial (BPJS) Kesehatan Kantor Cabang Lhokseumawe dimana kepemimpinan masih belum dapat menerapkan mengoptimalkan seluruh sumberdaya manusia yang bekerja disebabkan adanya hubungan kekerabatan antara pekerja dengan pejabat daerah sehingga dukungan organisasi yang di berikan tidak berdasarkan pada hasil kerja dan ini berhubungan dengan pemberian nilai atas pekerjaan yang di lakukan pegawai sehingga menimbulkan rasa ketidakadilan di kalangan pegawai.

Oleh karena itu, berdasarkan uraian permasalahan tersebut diatas peneliti tertarik untuk melakukan penelitian mengenai Pengaruh Kepemimpinan, Dukungan Organisasi dan Keadilan terhadap Kinerja Pegawai Badan penyelenggara Jaminan Sosial (BPJS) Kesehatan Kantor Cabang Lhokseumawe".

Berdasarkan latar belakang yang dikemukan diatas, tujuan dari penelitian ini adalah untuk mengetahui dan menganalisis pengaruh :

1. Kepemimpinan terhadap Kinerja Pegawai Badan Penyelenggara Jaminan Sosial (BPJS) Kesehatan Kantor Cabang Lhokseumawe.
2. Dukungan Organisasi terhadap Kinerja Pegawai Badan Penyelenggara Jaminan Sosial (BPJS) Kesehatan Kantor Cabang Lhokseumawe.

3. Keadilan terhadap Kinerja Pegawai Badan Penyelenggara Jaminan Sosial (BPJS) Kesehatan Kantor Cabang Lhokseumawe.

4. Kepemimpinan, Dukungan Organisasi dan Keadilan terhadap Kinerja Pegawai Badan Penyelenggara Jaminan Sosial (BPJS) Kesehatan Kantor Cabang Lhokseumawe.

\section{Metode Penelitian \\ 2.1.Lokasi Penelitian}

Penelitian dilaksanakan di Badan penyelenggara Jaminan Sosial (BPJS) Kesehatan Kantor Cabang Lhokseumawe, Jln. Iskandar Muda No.01, Kp. Jawa Lama, Banda Sakti Kota Lhoksumawe, Nanggroe Aceh Darussalam, Kode Pos 24355

\subsection{Populasi}

Populasi adalah wilayah generalisasi yang terdiri atas obyek/subjek yang mempunyai kuantitas dan karakteristik tertentu yang ditetapkan oleh peneliti untuk dipelajari dan kemudian ditarik kesimpulannya. Yang menjadi populasi pada penelitian ini berdasarkan data pegawai secara keseluruhan di Badan Penyelenggara Jaminan Sosial (BPJS) Kesehatan Kantor Cabang Lhokseumawe berjumlah 58 Orang.

\subsection{Sampel}

Sampel yang akan diambil dari populasi tersebut harus betul-betul representatif atau dapat mewakili. Dengan teknik penarikan sampel secara total sampling atau metode sensus, maka sampel dalam penelitian ini berjumlah 58 orang yang terdiri pada bidang bidang yang dianggap peneliti mempunyai konteribusi langsung pada variable yang di teliti

\subsection{Definisi Operasional Variabel}

Definisi operasional variable pada penelitian ini dapat dilihat pada table 1 berikut : 
Tabel 1

Definisi Operasional Variabel

\begin{tabular}{|c|c|c|}
\hline Variabel Penelitian & Definisi Operasional & Indikator \\
\hline $\begin{array}{l}\text { Kepemimpinan } \\
\text { (X1) }\end{array}$ & $\begin{array}{l}\text { Kepemimpinan adalah cara mengajak } \\
\text { karyawan agar bertindak benar, } \\
\text { mencapai komitmen dan memotivasi } \\
\text { mereka untuk mencapai tujuan } \\
\text { bersama (Sudarmanto,2009:133).) }\end{array}$ & $\begin{array}{l}\text { - Bersifat Adil } \\
\text { - Memberi sugesti } \\
\text { - Mendukung tujuan }\end{array}$ \\
\hline $\begin{array}{l}\text { Dukungan } \\
\text { Organisasi (X2) }\end{array}$ & $\begin{array}{l}\text { dukungan organisasi didefinisikan } \\
\text { sebagai suatu keyakinan tentang } \\
\text { sejauh mana organisasi memberikan } \\
\text { nilai kontribusi dan peduli akan } \\
\text { kesejahteraan mereka. Eisenberger } \\
(2006: 209)\end{array}$ & $\begin{array}{l}\text { - Penghargaan } \\
\text { - Pengembangan } \\
\text { - Kondisi Kerja } \\
\text { - Kesejahteraan Karyawan }\end{array}$ \\
\hline Keadilan (X3) & $\begin{array}{l}\text { Keadilan organisasi didefinisikan } \\
\text { sebagai sebuah konsep yang } \\
\text { menyatakan persepsi karyawan } \\
\text { mengenai sejauh mana mereka } \\
\text { diperlakukan secara wajar, dalam } \\
\text { organisasi dan bagaimana persepsi } \\
\text { tersebut mempengaruhi } \\
\text { hasilorganisasi seperti komitmen dan } \\
\text { kepuasan. Pratiwi(2005:55) }\end{array}$ & $\begin{array}{l}\text { - Kesempatan Promosi yang } \\
\text { adil } \\
\text { - Pengakuan Kerja Keras } \\
\text { - Prosedur Pengakuan } \\
\text { Kinerja yang adil } \\
\text { - Sikap Atasan Yang Adil } \\
\text { - Penilaian Kinerja yg } \\
\text { Sesuai Dengan yang } \\
\text { Seharusnya } \\
\text { - Penghargaan yang } \\
\text { didasarkan Keterampilan } \\
\text { dan Pendidikan } \\
\end{array}$ \\
\hline $\begin{array}{l}\text { Kinerja Pegawai } \\
(\mathrm{Y})\end{array}$ & $\begin{array}{l}\text { Kinerja adalah hasil dari satu yang } \\
\text { dilakukan seseorang dan menghasilkan } \\
\text { apa yang di sepakati sesuai dengan } \\
\text { kesepakatan yang di lakukanJackson } \\
(2006: 367)\end{array}$ & $\begin{array}{l}\text { - Kualitas } \\
\text { - Kuantitas } \\
\text { - Keandalan } \\
\text { - Bekerja Sama } \\
\text { - Ketepatan Waktu }\end{array}$ \\
\hline
\end{tabular}

\subsection{Teknik Analisa Data}

Tehnik analisa data yang digunakan pada penelitian ini dikumpulkan dari dua sumber, yakni dilakukan dengan melakukan pengolahan data dengan beberapa uji yang dilakukan dengan uji validitas, uji reabilitas, uji asumsi klasik, uji regresi sampai dengan uji hipotesa yaitu uji f dan uji t serta determinasi.

\section{Analisis dan Pembahasan \\ 3.1. Analisis Regresi Berganda}

Dari Tabel 2 di bawah diperoleh model persamaan regresi berganda yang terbaik karena sudah memenuhi asumsi klasik sebagai berikut:

$$
Y=5,271+0.083 X_{1}+0,833 X_{2}+0,331 X_{3}
$$

Tabel 2

Koefisien Regresi Berganda

Coefficients $^{\mathrm{a}}$

\begin{tabular}{|l|r|r|r|r|r|}
\hline \multirow{2}{*}{ Model } & \multicolumn{2}{|c|}{ Unstandardized Coefficients } & $\begin{array}{c}\text { Standardized } \\
\text { Coefficients }\end{array}$ & \multirow{2}{*}{$\mathrm{t}$} & \multirow{2}{*}{ Sig. } \\
\cline { 2 - 4 } & \multicolumn{1}{|c|}{$\mathrm{B}$} & Std. Error & \multicolumn{1}{|c|}{ Beta } & & \\
\hline (Constant) & 5.271 & 3.716 & & 1.418 & .162 \\
$\mathrm{X} 1$ & .083 & .073 & .087 & 1.130 & .000 \\
$\mathrm{X} 2$ & .833 & .076 & .836 & 10.906 & .000 \\
$\mathrm{X} 3$ & .331 & .057 & .335 & .548 & .000 \\
\hline
\end{tabular}

a. Dependent Variable: $Y$ 
Persamaan regresi linear berganda tersebut dapat diartikan sebagai berikut :

a. Jika variable beban kerja, Keadilan, dan lingkungan kerja 5,271 bernilai sama dengan nol, maka kinerja akan bernilai sebesar satuan dengan kecenderungan mengalami penurunan.

b. Jika variabel beban kerja ditingkatkan sebesar 1 satuan, maka kinerja guruakan meningkat sebesar 0,083 satuan.

c. Jika Keadilan ditingkatkan sebesar 1 satuan, maka akan diikuti dengan peningkatan kinerja guru sebesar 0.833 satuan.

Tabel 3

Hasil Uji t (Parsial)

Coefficients $^{\mathrm{a}}$

\begin{tabular}{|l|r|r|r|r|r|}
\hline \multirow{2}{*}{ Model } & \multicolumn{2}{|c|}{ Unstandardized Coefficients } & $\begin{array}{c}\text { Standardized } \\
\text { Coefficients }\end{array}$ & \multirow{2}{*}{$\mathrm{t}$} & \multirow{2}{*}{ Sig. } \\
\cline { 2 - 4 } & \multicolumn{1}{|c|}{$\mathrm{B}$} & Std. Error & \multicolumn{1}{|c|}{ Beta } & & \\
\hline (Constant) & 5.271 & 3.716 & & 1.418 & .162 \\
$\mathrm{X} 1$ & .083 & .073 & .087 & 1.130 & .000 \\
$\mathrm{X} 2$ & .833 & .076 & .836 & 10.906 & .000 \\
$\mathrm{X} 3$ & .331 & .057 & .335 & .548 & .000 \\
\hline
\end{tabular}

a. Dependent Variable: $Y$

Dari table 3 diatas diketahui bahwa nilai signifikansi dari nsi $\left(\mathrm{X}_{1}\right)$ adalah 0.000 nilai ini lebih kecil dari nilai alphanya yang sebesar 0.05 . Dengan demikian dapat dinyatakan bahwa kecerdsan emosionalmemiliki pengaruh signifikanterhadap Kinerja. Selanjutnya diketahui bahwa nilai signifikansi dari Dukungan Organisasi $\left(\mathrm{X}_{2}\right)$ adalah 0.000 nilai ini lebih kecil dari nilai alphanya yang sebesar 0.05 . Dengan demikian dapat dinyatakan bahwa Dukungan pengaruhsignifikan d. Jika lingkungan kerja ditingkatkan 1 satuaan, maka akan diikuti dengan peningkatan kinerja sebesar 0,331 satuan

\subsection{Uji Hipotesa}

\subsubsection{Uji Parsial (Uji t)}

Pengujian hipotesis untuk uji t (uji partial) dilakukan untuk melihat pengaruh masingmasing variabel bebas terhadap variabel tidak bebas. Dari Tabel 3 dibawah diperoleh nilai $t_{\text {hitung }}$ dari setiap variabel bebas dan kemudian dibandingkan dengan nilai $t_{\text {tabel }}$ yang dipertoleh dari tabel T. 
Untuk dapat mengetahui besarnya Kinerja dapat dilihat pada koefisien Kepemimpinan, Dukungan Organisasi, determinasinya yang berada pada tabel 5 Keadilan berpengaruh signifikan terhadap berikut

Tabel 5

Koefisien Diterminasi $\left(\mathrm{R}^{2}\right)$

\begin{tabular}{|r|r|r|r|r|}
\hline Model & \multicolumn{1}{|c|}{$\mathrm{R}$} & $\mathrm{R}$ Square & $\begin{array}{c}\text { Adjusted R } \\
\text { Square }\end{array}$ & $\begin{array}{c}\text { Std. Error of the } \\
\text { Estimate }\end{array}$ \\
\hline $.885^{\mathrm{a}}$ & .783 & .771 & 1.74545 & $.885^{\mathrm{a}}$ \\
\hline
\end{tabular}

Berdasarkan pada tabel 5 diketahui bahwa nilai R-Square adalah sebesar 0,783. Artinya bahwa Kepemimpinan,Dukungan Organisasi dan Keadilanmampu menjelaskan Kinerjaadalah sebesar $78,3 \%$ sisanya $21,7 \%$ dijelaskan oleh variabel lain yang tidak dimasukkan ke dalam model penelitian ini..

\section{Kesimpulan}

1. Terdapat pengaruh yang signifikan Kecerdasan Emosional terhadap kinerja pegawai di Badan Penyelenggara Jaminan Kesehatan (BPJS) Kesehatan Cabang Lhokseumawe sebesar 0,088terhadap kinerja pegawai sehingga dapat di simpulkan Kecerdasan Emosional yang memadai dapat menentukan Kinerja pegawai juga akan tinggi walaupun ada variable lain yang mendukung untuk melihat hasil kinerja seorang pegawai .

2. Terdapat pengaruh yang signifikan Karakteristik Pekerjaan terhadap kinerja diBadan Penyelenggara Jaminan Kesehatan (BPJS) Kesehatan Cabang Lhokseumawe sebesar 0,014 dapat disimpulkan bahwa Karakteristik Pekerjaan akan dapat memiliki hasil yang tinggi jika pegawai memiliki Karakteristik Pekerjaan yang baik.

3. Motivasi pegawai berpengaruh terhadap Kinerja pegawai sebesar 0,887 dan signifikan ini menunjukan bahwa Motivasi dapat meningkatkan kinerja,

4. Kecerdasan Emosional,Karakteristik Pekerjaan dan Motivasi secara bersama sama berpengaruh signifikan terhadap Kinerja pegawai diBadan Penyelenggara Jaminan Kesehatan (BPJS) Kesehatan Cabang Lhokseumawe, adalah sebesar $85 \%$ sedangkan sisanya sebesar $15 \%$ dijelaskan oleh variabel lain yang tidak dimasukkan ke dalam model penelitian ini.

\section{DAFTAR PUSTAKA}

Adawiyah, Kurniatul. (2015). Pengaruh Keadilan Distributif Kompensasi dan Gaya
Kepemimpinan Transfoemasional terhadap Komitmen Afektif Karyawan JNE Banten dengan Kepuasan Kerja sebagai Variabel Intervening. Tesis MM UMY. Yogyakarta. Tidak Dipublikasikan

Almustofa (2014), Pengaruh Dukungan, Organisasi dan Keadialan Terhadap Kinerjapegawai (Studi pada pegawai Perum Bulog Divisi Regional Jakarta)

Arikunto, Suharsimi. (2008). Prosedur Penelitian Suatu Pendekatan Praktik. Jakarta: Rineka Cipta.

Beilharz(2009), peter. Ed. Teori-Teori Sosial. (Social Theory: A Guide to Central Thinkers). Diterjemahkan oleh: Sigit Jatiko.Cetakan I. Yogyakarta. Pustaka Pelajar

Dessler, Garry (2009), Manajemen Sumber Daya Manusia, PT. Preshelindo, Jakarta.

Handoko T, Hani (2008), Manajemen Personalia dan Sumber Daya Manusia, Edisi Kedua, BPFE Yogyakarta.

Haryati (2013), Pengaruh dan Dukungan OrganisasiTerhadap KinerjaPegawai pada dinas Kesehatan Kota Cimahi

Hasibuan, Malayu, SP (2010), Manajemen Sumber Daya Manusia,PT.Bumi Akasara Jakarta.

Muhibbin, Syah (2011), Manajemen Sumber Daya Manusia, Edisi Ketiga, Cetakan Keempat, Ghalia Jakarta

Mahmudi. 2010. Manajemen Kinerja Sektor Publik. UPP STIM YKPN, Yogyakarta

Nana Sujana, 2010Manajemen Sumber Daya Manusia. Edisi Revisi. Cetakan Kedua. Denpasar: Astabrata

Rivai, Veithzal dan Sagala, Ella Jauvani. (2012). Manajemen Sumber Daya Manusia Untuk Perusahaan : Dari Teori ke Praktek. Jakarta : PT. Rajagrafindo Persada

Robbins,S, 2008. Perilaku Organisasi, Edisi Kedua- belas, Penerbit Salemba Empat,Jakarta. 
Siagian P. Sondang (2009), Organisasi Kepemimpinan dan Prilaku Organisasi, Gunung Agung Jakarta

Sidanti (2015), Pengaruh Kepemimpinan dan Disiplin Kerja,Terhadap Kinerja Pegawai DPRD Kabupaten Madiun

Simamora, H. 2009. Manajemen Sumber Daya Manusia. Edisi Ketiga. Yogyakarta: Sekolah Tinggi Ilmu Ekonomi YKPN
Widari (2016), Pengaruh kepemimpinan, Dukungan organisasiTerhadap KinerjaPegawai BKD DIY.

Yulianthini (2012), Pengaruh Kepemimpinan dan KeadilanTerhadap Kinerja Pegawai Pada Distanak Kabupaten Buleleng 